\title{
A Seriedade no Conhecimento
}

\author{
The Seriousness of the Knowledge
}

Ronie Alexsandro Teles da Silveira *

$\begin{array}{r}\text { recebido: } 09 / 2012 \\ \text { aprovado: } 02 / 2013 \\ \hline\end{array}$

\begin{abstract}
Resumo:
A seriedade é geralmente compreendida como uma contrapartida psicológica natural da dedicação humana ao conhecimento. Entretanto, a análise apresentada aqui demonstra que ela é um componente do ethos da travessia: uma situação epistemológica e moral particular em que o homem visa um objeto distante, transcendente e superior. Essa situação é típica de algumas formas tradicionais de conhecimento religioso, filosófico e científico. A questão fundamental a ser discutida aqui diz respeito à pertinência ou não desse ethos diante da situação contemporânea do conhecimento e do sujeito. Na sequência, verificamos que a intensificação dos valores democráticos na sociedade atual tem produzido um abandono gradativo das relações hierárquicas, inclusive no âmbito epistemológico. Dessa maneira, o homem não busca mais valores transcendentes e superiores, já que se entende como sua fonte exclusiva. Isso torna claro que o ethos da travessia perdeu sua utilidade e que a seriedade não é mais uma virtude requerida pela relação atual que estabelecemos com o conhecimento. Ela é apenas um velho hábito herdado do passado que não possui mais nenhuma função epistemológica.

Palavras-chave: seriedade; epistemologia; democracia; narcisismo; imanência
\end{abstract}

\section{Abstract:}

The seriousness is generally understood as a natural psychological counterpart of human devotion to knowledge. However, the analysis presented here demonstrates that it is a component of the ethos of the crossing: a particular moral and epistemological situation in which man seeks a distant,

Graduação em Filosofia pela Universidade Federal de Goiás, Mestrado em Filosofia Transcendental e Dialética pela Universidade Federal do Rio Grande do Sul e Doutorado em Psicologia pela Pontifícia Universidade Católica do Rio Grande do Sul.Prof. na Universidade Federal da Integração Internacional da Lusofonia Afro-brasileira (UNILAB). em@il: roniesilveira@yahoo.com.br 
transcendent and higher object. This situation is typical of some kinds of traditional religious, philosophical and scientific knowledge. The fundamental question to be discussed here concerns the relevance or otherwise of that ethos on contemporary situation of the knowledge and subject. Further, we found that the intensification of democratic values in today society have produced a gradual abandonment of hierarchical relationships, including the epistemological framework. Thus, the man no longer seeks transcendent and higher values, since it sees as its exclusive source. This makes clear that the ethos of the crossing has lost its usefulness and the seriousness is no longer a virtue required by the current relationship we have with the knowledge. It is just an old habit inherited from the past that no longer has any epistemological function.

Keywords: seriousness; epistemology; democracy; narcissism; immanence

“A grácil besta humana parece perder o seu bom humor sempre que se põe a bem pensar; torna-se séria"

(Nietzsche, 1895/1976, p. 210)

\section{O Ethos da Travessia}

Com o conhecimento não se brinca. Em geral, nós o entendemos como uma atividade que exige seriedade e compenetração. Para obtê-lo se requer determinação e disposição para seguir adiante, através de uma série de etapas que devem ser superadas, sem que a atenção seja desviada ou perdida no trajeto. Essa seriedade se reflete em constância psicológica, em uma disposição subjetiva para ir além de um limite aparente, porque se acredita que o conhecimento não nos é dado de forma imediata.

A seriedade no conhecimento é uma espécie de arco com o qual atiramos uma seta em um alvo distante e velado - embora se tenha, desde o início, indícios de onde ele se encontra. São as 
hipóteses que orientam a mão que tensiona o arco. Ninguém mira no vazio, mas em alguma região específica onde se acredita que o alvo pode estar. A seriedade é uma tensão, uma expectativa de que o alvo está lá e de que devemos orientar e reorientar permanentemente a seta do conhecimento na sua direção. Ao contrário de uma flecha real que não pode ter seu trajeto corrigido depois do lançamento, o rumo da seta epistemológica pode ser sempre reestabelecido por meio da mudança dos termos do problema, pela substituição das hipóteses ou pelo abandono dos pressupostos de onde partimos no início.

$\mathrm{Na}$ verdade, a seriedade é a contrapartida psicológica da situação epistemológica caracterizada pela distinção entre uma realidade distante e uma aparência próxima do sujeito. É a crença nessa distância que faz com que a atenção do investigador não se detenha no que é imediato e disponível à primeira vista. É ela que potencializa as operações de profundidade, de trespassamento daquela aparência que deve ser descartada em benefício de um conhecimento superior. A obtenção desse último se realiza sempre em algum ponto distante daquele em que nos encontramos no início do conhecimento.

A seriedade é uma disposição que nasce em nós quando acreditamos que o conhecimento é um processo. Assim, ir além de onde nos encontramos, seja no sentido empírico ou no sentido conceitual, se torna possível em função da crença de que há um objeto velado do conhecimento: um alvo distante que pode ser atingido quando desencadeamos o processo de conhecer. A tensão psicológica é uma preparação para levar adiante esse processo, ultrapassar a aparência e atingir o alvo da essência.

Sem a seriedade, é provável que nos detivéssemos no que é imediato e não nos dispuséssemos à empreitada de seguir um longo caminho. Ela é uma determinação fixa, uma disposição de 
espírito que nos fortalece para o necessário afastamento das ilusões iniciais requeridas pelo processo epistemológico de aproximação com relação à verdade.

Essa rigidez é diretamente proporcional à distância a ser percorrida até o que se julga ser a posse definitiva da verdade. Um homem é tanto mais rígido quanto crê que seu objeto de conhecimento esteja distante. Quanto maior for a distância, maior a rigidez necessária para transpô-la. Só uma grande reserva de energia pode manter a seta na direção correta e fazêla chegar ao alvo. Para isso, a mão que verga o arco deve se manter firme e ser capaz de concentrar em si a energia necessária. Sem essa energia, a seta descreveria uma parábola curta e se perderia nas proximidades de onde partiu.

A mão que verga o arco do conhecimento precisa calcular a distância até o alvo. Por isso, a seriedade que expressamos está diretamente ligada ao cálculo da distância que julgamos dever superar: para objetos próximos se requer pouca força e rigidez, para objetos longínquos se exige muita tensão concentrada no braço do arqueiro.

A solenidade de algumas atividades ligadas ao conhecimento, o ritual e a reverência com a qual nos aproximamos das atividades epistemológicas estão ligados à distância que acreditamos existir entre nós e o alvo. O respeito é tanto maior quanto nos sentimos distantes do objeto definitivo do conhecimento. Entre todos os demais, os homens religiosos são certamente os mais rígidos. Para eles, quase não há esperança de estar na posse definitiva do seu objeto de conhecimento, do núcleo de valor das coisas importantes. De fato, isso só ocorre em situações muito excepcionais mesmo para os mais fiéis. No caso do conhecimento religioso, embora o alvo seja dotado de extremo valor, se tem pouca expectativa de poder alcançá-lo integralmente. Para chegar a Deus se requer uma grande quantidade de energia e a determinação de uma vida inteira, uma disposição inabalável conhecida como fé. 
Deus é um assunto extremamente sério, porque se encontra muito distante dos homens. Quem pretende chegar a ele precisa estar seguro de si, da distância e do caminho. Nesse caso, a rigidez é tão grande que inviabiliza a mudança de trajeto ou correções posteriores. Quando se trata de Deus e de seu conhecimento, improvisações não são bem vindas.

Essa situação certamente só se apresentou na história da humanidade com o advento do monoteísmo. É a partir da representação religiosa de um ser superior destituído de história pessoal e de feição empírica que Deus começa a ser procurado como uma entidade que se encontra distante do homem (HEGEL, 1830/1987). É justamente a crença na transcendência divina com relação ao mundo humano que estabelece a distância a ser eliminada por um processo de aproximação. E é a partir desse distanciamento inicial entre o mundo dos homens e o reino de Deus, que a seriedade torna-se um componente psicológico do processo de busca por conexão. Essa aproximação tanto pode ocorrer por meio de uma identificação direta, uma experiência prática, como através de um conhecimento teórico superior. $\mathrm{O}$ que importa aqui é perceber que com o monoteísmo se estabelece uma transcendência a ser superada, que o homem passa a calcular a distância que o separa do valor superior e que se capacita psicologicamente para a empreitada ao se revestir de extrema seriedade - em função da extrema distância.

Um Deus distante requer, da parte de quem quer conhecêlo, uma disposição de espírito vigorosa que o conduza para além desse mundo material. O monoteísmo estabelece uma situação em que se requer a maior energia psicológica para as atividades de aproximação - justamente porque nele os homens estão muito distantes de Deus. Também é aqui que se encontram os homens moralmente mais rígidos: aqueles que procuram resumir em alguns poucos mandamentos tudo o que faz parte do 
comportamento necessário para ingressar no reino de Deus.

$\mathrm{Na}$ verdade, a rigidez de caráter é um método de aproximação, a definição de uma estratégia psicológica para a superação da distância entre os homens e Deus. Ela é uma preparação prévia sem a qual o homem não está habilitado a iniciar o processo de busca. Há aqui a necessidade de adoção de uma postura psicológica prévia, uma concentração sobre si mesmo, um cálculo relativo à distância que nos separa do alvo. A rigidez é uma condição para levar adiante o processo de aproximação com relação a esse objeto distante.

Em função da exposição à distância que separa o homem de seu objeto de conhecimento e da necessidade da manutenção de um patamar elevado de energia psíquica para enfrentá-lo é que se forma o caráter. A disposição para lançar longe a seta em direção ao objeto se torna permanente e converte-se em uma qualidade do homem que procura. Os homens de caráter são aqueles que miram longe e incorporam a tensão do arco em sua própria maneira de ser. As religiões monoteístas são religiões da seriedade. Como nelas se afirma a existência de um Deus superior, sua posse exige disposições de espírito permanentes e a formação do caráter e da constância requeridas pela travessia.

O conhecimento científico, desde sua formulação inicial por Descartes (1637/1979) e Bacon (1620/1999), postula a necessidade de um método. Um método é justamente a escolha de uma estratégia de aproximação com um objeto transcendente, uma forma de se chegar a ele abandonando tudo o que é aparente e lateral. Ele é um artifício preparatório que deve ser incorporado, como se fosse o caráter epistemológico do cientista, como se fizesse parte do seu ser. Não é ocasional que o método seja compreendido como uma via segura para o conhecimento. De fato, é justamente isso que ele pretende ser: uma fonte de acesso padronizada, um caminho. O método implica em uma depuração psicológica e comportamental por parte do cientista, uma purificação que exige o abandono de 
disposições inadequadas ao conhecimento. Esse aspecto é evidenciado pela Teoria dos Ídolos de Bacon (1620/1999): o conjunto de crenças e valores que devem ser abandonados em benefício do método que leva ao conhecimento autêntico.

Com isso, podemos reconhecer que a ciência se encontra na mesma condição funcional do conhecimento religioso monoteísta: em ambos o sujeito se encontra inicialmente privado da posse de um objeto que julga possuir grande valor. Por sua vez, a crença nessa distância impõe a necessidade de um processo que levará à posse de seu objeto. E a viagem requer uma disposição psicológica, seja a constituição do caráter moral religioso ou do caráter moral científico. Ambos são "devotos", ambos se dispõem ou se dedicam à empreitada de aproximação com respeito ao alvo. Ambos se preparam para realizar uma viagem em direção à transcendência de maior valor.

$\mathrm{Na}$ medida em que observamos essa identidade funcional entre a adoção de um caráter rígido e de um método científico, podemos verificar a natureza moral desse último. O método na ciência nada mais é que a definição de um ethos da travessia, de um preparo psicológico que viabiliza a viagem para a superação da transcendência com relação ao objeto do conhecimento superior. Para utilizar uma linguagem ao gosto de Bacon (1620/1999), podemos dizer que assim como um crente deve se mostrar moralmente preparado para ingressar no reino de Deus, um cientista deve ser mostrar metodologicamente pronto para ingressar no reino dos homens (a interpretação da natureza).

Além da religião e da ciência, algumas modalidades de pensamento filosófico, ao afirmarem a distinção entre realidade e aparência, alinham-se na proposição de alguma modalidade de ethos da travessia como requisito para o conhecimento. A crença na existência de um estágio inicial, empírico ou conceitual, do conhecimento que necessita ser abandonado ou elaborado em benefício de uma maior aproximação com a realidade é a consequência dessa distinção. O que é imediato, 
sejam opiniões precárias ou sensações imediatas, deve dar lugar a um conhecimento superior e mais verdadeiro. Portanto, em suas várias versões platônicas, o conhecimento é entendido como um processo que leva da opinião à verdade, do imediato ao mediato, do próximo ao distante, do inferior ao superior.

Para transpor o intervalo que separa a crença no que é aparente da posse da realidade se requer aquela disposição de espírito que agora pode ser mais bem entendida. A seriedade é uma disposição psicológica para percorrer grandes distâncias epistemológicas, para entrar na posse do valor transcendente e superior. É ela que nos dá fôlego para essa viagem, que retém, conserva e dispõe da energia psíquica necessária para superar os obstáculos do processo de conhecimento. Ela nasce quando se estabelece, no plano epistemológico, uma diferença entre uma situação fatual inferior e um ideal superior a ser conquistado por meio do conhecimento - religioso, científico ou filosófico.

Os homens que separam a aparência da realidade são tensos. Enquanto homens que postulam a necessidade da travessia em direção a um âmbito superior, suas vidas são setas orientadas para o além, para a realidade em cuja posse eles gostariam de estar. Os homens que se empenham no processo de conhecimento de um objeto distante e superior, carregam consigo $\mathrm{o}$ peso da tensão necessária para essa viagem. $\mathrm{O}$ método e a rigidez de caráter constituem-se como pesos adicionais espontaneamente acrescentados por esses viajantes. As reservas que eles guardam se amalgamam a seus corpos e tornam a viagem lenta - em função do sobrepeso. Curiosamente, é justamente aquilo com o qual eles se guarneceram para a travessia que torna a viagem lenta. Seus próprios corpos, agregados e sobrecarregados de metodologia e de caráter, são a expressão da distância que julgam ter que percorrer: quanto maiores eles são, maior é a distância que julgam estar pela frente. A velocidade no conhecimento é inversamente proporcional ao ethos da travessia. 


\section{Servilidade e reverência}

A distinção entra a aparência e a realidade cria a transcendência. Daí surgem os homens sérios e pesados, cuja existência é marcada pela necessidade de transposição de um afastamento indesejado. A moralidade que eles adotam é a energia que julgam necessária para a travessia, o fôlego que aspiram e incorporam antes do início da viagem. $\mathrm{O}$ peso da vida de tais homens é a expressão da distância que eles calculam existir entre seu conhecimento atual e o conhecimento que julgam ser a expressão acabada da realidade, entre o valor de fato e o valor que se deseja. A seriedade é um componente da preparação para a posse da verdade, para a obtenção de um reino dos céus do conhecimento.

Há algo de comum em todos os casos em que a seriedade surge como um comportamento requerido para o conhecimento, em que as atividades epistemológicas envolvem algum grau de solenidade, em que se observa a presença do ethos da travessia. Em todas essas situações, os homens encontram-se fora do centro do valor. É o reconhecimento da situação de alienação do homem frente à fonte de toda legitimação que estabelece a base para a adoção do ethos da travessia. O homem só se dispõe à empreitada da procura, se reconhece que está privado daquele objeto que constitui um bem maior. Sem a percepção da carência e da falta de valor interno, não haveria busca pelo complemento, pelo valor exterior.

Não se trata, portanto, somente do reconhecimento de que há um valor transcendente e sim da crença de que tal valor é superior ao valor do próprio homem. Esse só se dispõe a uma jornada se houver, lá fora, algo pelo qual vale a pena empreendê-la, um valor que deve ser superior e do qual a posse ou o contato justificam o esforço da travessia. Dessa maneira, 
tanto esse ethos quanto o seu componente psicológico sério se conectam com uma hierarquia de valores em que o homem ocupa uma posição inferior.

É o reconhecimento da existência de um valor superior transcendente que se encontra no cerne da adoção da seriedade como comportamento moral para o conhecimento, como uma virtude epistemológica. Ela é o produto reverente da alienação do homem com relação ao valor epistemológico superior. Nesse sentido, a seriedade é uma manifestação da servilidade, do fato do homem ser devoto ou estar a serviço de um valor superior. Os homens sérios no conhecimento são, segundo suas próprias disposições subjetivas, inferiores ao seu objeto de conhecimento. Sua seriedade é uma constante reverência a algo maior, suas solenidades e rituais são a reafirmação de um estado de inferioridade humana e de comportamento respeitoso diante de algo mais valioso do que eles.

O ethos da travessia é um ethos de homens alienados, que se julgam fora do centro dos valores superiores e que buscam legitimação em uma instância diferente daquela em que eles se encontram. A busca pelo conhecimento verdadeiro é homóloga à busca pela obtenção de referência moral: ambas são atitudes de homens que se consideram destituídos de valor ou, pelo menos, dotados de um valor inferior.

\section{Crise da Hierarquia}

Estabelecido o ethos da travessia e a maneira como a seriedade se constitui como um de seus elementos, temos que analisar se tal disposição psicológica ainda é requerida pelas atividades atuais de conhecimento. Verificamos que esse ethos só adquire sentido no contexto de um conjunto de pressupostos caracterizado pela afirmação de um valor transcendente superior. Somente ele pode estabelecer uma hierarquia e 
mobilizar os homens para a travessia da distância. Então, nossa questão passa a ser a da persistência ou não de um valor transcendente superior no campo do conhecimento atual.

A pergunta sobre a situação atual do conhecimento envolve uma grande dose de generalização. Considero que esse risco se amplia em função da dimensão do presente trabalho e do aspecto incompleto da presente exposição. Assim, o leitor deve considerar que o diagnóstico sobre o estágio atual do conhecimento possui, aqui e em função das condições desse texto, uma característica dogmática. Apenas uma exposição mais longa permitiria eliminá-la.

A situação atual do conhecimento nos parece corresponder, nos seus aspectos principais, àquela identificada por Lyotard (1979/2002) no final dos anos 70. Segundo ele, a lógica de produção do conhecimento deixou de ser conduzida em termos hierárquicos. Isso significa que na esfera particular de uma ciência ou de uma forma de conhecimento (o domínio específico de uma linha ou de um grupo de pesquisa) não se requer mais nenhum processo de legitimação externo. Sem a necessidade de busca por fundamentos exteriores, cada instância epistemológica passa a valer por si mesma. Sua legitimação ocorre de maneira interna, em função do atendimento a regras ou procedimentos que ela própria estabelece ou, de forma implícita, apenas por meio de sua própria existência. Nesse último caso, é o fato de sua existência que a torna legítima.

Vamos considerar um modelo histórico anterior para facilitar a comparação com a situação recente descrita por Lyotard. O modelo tradicional de conhecimento fundamentado possui suas raízes histórias no pensamento de Aristóteles. Esse entende que o conhecimento é caracterizado por uma relação causal. Sua realização plena implica em seguir os nexos de causalidade entre vários fenômenos de maneira a estabelecer uma longa cadeia explicativa unindo causas e efeitos. Cada nó dessa cadeia é consequência de uma causa anterior e funciona 
como causa de uma nova consequência posterior.

Para evitar o regresso ao infinito causal, em que a cadeia se perderia no vazio de uma progressão sem fim, Aristóteles afirma a existência de um elemento que seria causa de si mesmo e que forneceria o fundamento último ao edifício do conhecimento.

Esse modelo tradicional pode ser entendido a partir de uma metáfora arquitetônica em que algumas partes dão sustentação a outras até que se chegue à base definitiva ou ao fundamento autofundante: o ser enquanto ser - um procedimento epistemológico que ficou conhecido como fundacionismo (SILVEIRA, 1998). É esse elemento autofundante que será responsável por fornecer apoio às partes mais frágeis e não fundadas em si mesmas, os nós subsequentes da cadeia causal. Um conhecimento subordinado se torna legítimo quando suas bases estão bem assentadas em princípios conectados causalmente a ele. Há um processo de transferência de legitimidade epistemológica desde os últimos fundamentos até as instâncias inferiores, isto é, àqueles destituídos de autossuficiência epistemológica.

Como resultado, teríamos um sistema geral do conhecimento hierarquizado com formas de conhecimento superiores e inferiores, de acordo com sua posição na série causal de legitimação. Como ela possui uma cúpula superior, as posições relativas podem ser determinadas com relação à distância em que se encontram da causa de si mesmo. Cada forma particular de conhecimento deriva sua legitimidade de outra forma superior e ocupa um lugar específico na hierarquia do sistema geral.

A partir dessa moldura tradicional, podemos compreender melhor a situação que Lyotard (1979/20002) descreve. O seu diagnóstico corresponde ao resultado da ruptura do processo de legitimação, de tal maneira que as formas particulares de conhecimento não se articulam mais em um sistema geral que 
propicia fundamento para suas partes. Com essa ruptura, cada uma das formas particulares de conhecimento produz seus próprios critérios de legitimação. Esses, na verdade, não constituem uma parte independente das operações epistemológicas particulares. Pelo contrário, eles também fazem parte de tais operações e são internas a cada instância particular - podendo, inclusive, funcionar como regras implícitas do que é aceitável ou não. Assim, é como se a corrente do sistema causal aristotélico tivesse se rompido e cada elo funcionasse segundo seus próprios princípios, livre do constrangimento da posição hierárquica em que se encontrava.

Sendo assim, não se requer mais uma busca por fundamentos exteriores que seriam os responsáveis pela transmissão de legitimação, não há mais necessidade de dar organicidade e constituir um sistema geral do conhecimento. $\mathrm{Na}$ verdade, perde-se a perspectiva do sistema e de sua articulação geral unitária. A nova legitimação converte-se em uma característica que deve ser identificada dentro de cada instância epistemológica. Seus requisitos de validade fazem parte apenas de sua própria existência particular.

A obtenção de valor epistemológico não se opera mais por aproximação com relação a um ponto dotado de superioridade e que possuiria a virtude adicional de transmiti-lo às instâncias inferiores. Nesse contexto não parece haver sentido em um movimento ascendente que nos levaria a um estágio em que a totalidade do processo de justificação obtivesse um sentido definitivo ou em que se revelasse um valor especial e superior.

Podemos dizer que há uma crise na hierarquia dos valores epistemológicos em função dessa fragmentação. Não se trata de uma crise de determinada hierarquia em função de sua constituição e sim de uma crise dos procedimentos fundacionais de estilo aristotélico. Trata-se, portanto, de uma crise do modelo hierárquico que permitia sistematicidade e ordenamento do conhecimento. A afirmação de que a legitimação é um 
procedimento imanente compromete qualquer tipo de hierarquia fundada sobre valores independentes superiores e qualquer noção de sistema do conhecimento.

\section{O Carrossel de Narciso}

Para ampliar o escopo do significado dessa crise da hierarquia vou caracterizar o impacto desses mesmos valores em outras esferas da cultura. Lipovetsky $(1987 ; 1992)$ denomina a sociedade das democracias liberais contemporâneas de frívola. Essa sociedade tornou-se frívola justamente em função de ter eliminado a função reguladora de um valor transcendente superior. No seu lugar, foi colocado o indivíduo autônomo. A situação cultural atual consiste na reversão da lógica predominante típica do mundo moderno, que girava em torno de valores permanentes e exteriores ao indivíduo.

A autonomia com a qual os indivíduos foram dotados significou uma brutal remodelação no plano dos valores. A partir da adoção dessa autonomia, só tem valor aquilo que é individual ou se conecta diretamente à subjetividade como sua forma de expressão. Esta última, ao invés de se realizar como busca pela posse de valores superiores, concentra-se em si mesma de maneira a dar vazão plena a suas próprias potencialidades interiores. Um indivíduo autônomo não necessita de nada de exterior, senão de condições para sua plena realização enquanto indivíduo. Ele encontra-se concentrado sobre si mesmo e reconhece a si mesmo como sendo dotado de valor - assim como as formas de conhecimento se tornam legítimas em função de seus próprios critérios internos. Dessa maneira, o culto narcisista e a busca pela realização plena da interioridade substituem o reconhecimento e a veneração de valores autônomos e superiores.

Um sinal dessa nova revolução copernicana narcisista é a 
busca permanente pela novidade, típica das sociedades industriais contemporâneas. A novidade consiste na procura por uma expressão diferente de sua própria personalidade, de uma nova maneira de se diferenciar dos demais. Os indivíduos procuram expressar quem são de maneira a se tornarem particulares e a revestirem sua individualidade de um valor único. Nessa trajetória eles se afastam da adoção de valores já aceitos ou de opiniões consagradas e procuram uma nova maneira de expressar quem são. Todos querem se tornar outros, de tal maneira que possam intensificar suas experiências e ampliar o âmbito de sua existência individual por meio da adoção de uma diferença específica. Todas as diferenças passam a ser encaradas não como desvios de uma medida padrão, mas como formas autênticas de expressão das individualidades. Logo, a livre expressão das diferenças individuais é considerada como algo desejável por si mesmo.

Como o indivíduo passa a ocupar o centro de onde emergem os valores, é justamente na expansão da vida privada que os esforços se concentram. Isso não significa simplesmente abandonar modalidades culturais pré-existentes, mas em dotálas de novos significados. Assim, por exemplo, a religião passa a ser encarada como a ocasião para uma nova experiência subjetiva que não compromete o indivíduo com valores externos fixos. Ela é uma oportunidade para que o indivíduo possa ampliar sua subjetividade tornando-se budista ou cristão durante períodos de sua vida - eventualmente muito curtos. Note que, embora a religião esteja presente, ela não implica em uma atitude de reverência com relação a valores superiores, mas propicia à subjetividade autônoma uma nova experiência que a enriquece e funciona como suporte para sua realização. Isto é, trata-se sempre da necessidade narcisista do indivíduo em se expressar e em tornar sua experiência mais ampla e significativa. Sua subjetividade torna-se o centro até mesmo de sua relação com a religião. 
O uso de todos os bens culturais disponíveis é feito a partir desse mesmo princípio. Eles são utilizados como fontes de enriquecimento individual, como modalidades de ampliação da psiquê contemporânea, como expressões do eu. A totalidade da cultura é colocada à inteira disposição do homem, como um conjunto de recursos que servem a ele. Ela torna-se um conjunto de bens à disposição do indivíduo, uma mercadoria que pode ser consumida em função de propósitos específicos de cada indivíduo.

Embora a produção se dê em escala industrial e gere produtos homogêneos, o importante é que cada um deles amplie a possibilidade de expressão individual. Assim, se faz necessária também uma indústria cultural que coloca ao alcance de todos os indivíduos novas possibilidades de expressão e de experiências de vida. Isso não significa uniformização e padronização como pode parecer. Pelo contrário, ela potencializa a diferenciação na medida em que o indivíduo usufrui do valor de uso de cada bem na medida em que ele serve como expressão de sua particularidade. Dessa forma, os bens desejáveis são aqueles que permitem uma apropriação individual e a expressão particular da subjetividade, embora sua produção seja feita em escala industrial. O que é desejável na relação de consumo é o valor de uso das mercadorias que permite a cada um ampliar sua individualidade além dos limites existentes.

O consumismo torna-se uma característica fundamental de uma sociedade orientada para o indivíduo na medida em que, como consumidor, ele se individualiza. Não apenas por adaptar o valor dos bens ao seu uso pessoal como também pela oportunidade de exercer continuamente a atividade de escolher. Isto é, na relação de consumo o homem confirma o valor absoluto de sua própria autonomia ao afirmar sua vontade pelo ato de escolha. Por meio dela, o homem afirma sua diferença individual e sua presença no mundo objetivo: ele é o centro das 
decisões. Como consumidor, Narciso se coloca no centro de um carrossel permanentemente renovável de novos objetos que buscam suprir suas necessidades e dar à sua subjetividade plena expressão concreta. As mercadorias estão aí para satisfazê-lo, embora ele permaneça sempre insatisfeito (Baudrillard, 1970) para além de qualquer escolha. Delas, só interessa o valor de uso e o quanto podem servir como substratos da expressão da individualidade particular.

O que é próprio da relação de consumo é que ela se desenvolve como uma atividade imanente: não há nenhum benefício exterior ao sistema de produção e circulação de mercadorias. Tudo o que interessa nele pode ser calculado por uma análise de custo e benefício (READINGS, 1996). Isto é, trata-se de uma relação em que tudo está disponível no mesmo patamar, sem hierarquia e sem transcendência.

No âmbito dessa relação horizontal não há um valor externo, nem qualquer indicação de que há uma distância a ser percorrida, de um trajeto a ser feito para algum outro lugar. $\mathrm{O}$ consumo é a afirmação de que o homem já se encontra no centro de todas as coisas e de que ele é a fonte que concede valor a tudo o mais: um bem só é um bem enquanto expressão da individualidade. O indivíduo já possui tudo o que importa, tudo o que tem valor - basta que ele escolha e expresse o que é, basta que ele se diferencie exteriormente dos demais. Nessa situação, o indivíduo já vale integralmente como indivíduo desde o início e não necessita conectar-se ou apoiar-se em nada que esteja fora de si mesmo para obter sua plena realização. No consumo não há valores dispostos em hierarquia, não há distância a ser suplantada, não há exterioridade. Na relação de consumo, o homem detém todo o valor que é relevante.

\section{A Decrépita Seriedade}


O quadro da situação contemporânea que elaborei certamente é muito simplificado e só pode dar uma ideia esmaecida dos valores vigentes. Concentrei-me somente naqueles elementos que parecem ser decisivos para os propósitos desse texto. Nesse sentido, acredito que o esquema acima pode se mostrar útil, mesmo não sendo exaustivo. Assim, creio que estamos razoavelmente aparelhados para avaliar a pertinência do ethos da travessia e do seu componente sério diante da situação do conhecimento e do sujeito em que nos encontramos no mundo contemporâneo.

Tanto no que denominei acima de crise da hierarquia quanto no que chamei de carrossel de Narciso não parece haver nenhuma função significativa para o ethos da travessia. Nossa condição epistemológica atual indica que uma hierarquia das formas de conhecimento construída por meio de correias de transmissão do poder de justificação não é mais requerida. Assim, qualquer forma particular de conhecimento encontra em si mesma o mecanismo de sua legitimidade, não sendo necessário obtê-la em outra parte, muito menos em uma instância superior.

Isto significa que não há nenhuma distância entre a forma atual de nossa condição epistemológica e uma suposta existência ideal dela, uma que seja melhor ou mais substantivamente justificada. Não há um processo no qual tenhamos que nos engajar para obter outra forma superior de legitimidade. A justificação atual das formas de conhecimento é imanente à sua existência e inteiramente suficiente diante das demandas vigentes. Não há um estágio precário de conhecimento que viria a servir de base para um conhecimento fundamentado ou epistemologicamente superior.

$\mathrm{Na}$ verdade, não há qualquer sentido em se fazer uma distinção entre duas condições epistemológicas: uma que existe de fato e a outra que se constitui como um ideal e que funcionaria como critério definitivo de conhecimento legítimo. 
A eliminação desse ideal epistemológico distante, crucial para a constituição do ethos da travessia, resulta em que as questões de justificação têm de se resolver no âmbito do conhecimento fatual, sem recurso a nenhuma instância supostamente superior.

Não havendo uma diferença entre o conhecimento que existe e o que desejaríamos obter, não há mais distância a ser percorrida: o hiato entre o fatual e o ideal desapareceu e, com ele, os critérios de correção epistemológica independentes. Tal situação desmobiliza o ethos da travessia na mesma proporção em que recoloca a questão epistemológica em termos imanentes. A justificação é uma questão puramente fatual, logo interna a cada forma de conhecimento particular. Não se requer mais uma moldura ou um sistema geral que permita enquadrar as manifestações isoladas do saber. Cada uma delas vale por si própria sem ter que prestar constas a eventuais esferas superiores de significado. Elas não se submetem à transcendência.

Da mesma forma, a mudança do conhecimento em mercadoria o transforma em um ser cujo sentido está intimamente ligado ao valor de uso que ele adquire para o indivíduo. Isto é, o valor do conhecimento não é mais conferido por meio da concordância com outros valores independentes: ele sempre se define em função dos interesses particulares de cada pessoa. A informação é, portanto, um conhecimento desconectado de raízes profundas de sentido, de contextos gerais de significado, de tal forma que possa ser adaptada às necessidades individuais. A informação é um conhecimento flexível e disponível para ser utilizado livremente, de acordo com distintas funcionalidades.

Não há mais sentido em conferir um valor cultural absoluto e independente a qualquer conhecimento particular. Todo saber passa a ser informação: um conhecimento neutro, sem compromissos epistemológicos fixos, sem um sentido definitivo e cuja finalidade é apenas a utilização que dela faz o 
indivíduo. O conhecimento é um instrumento que deve servir à expressão e aos interesses da autonomia individual. Isto é, a informação é o conhecimento que vale para fins sempre circunstanciais e que possui a virtude de se adaptar a contextos particulares. Essa flexibilidade é resultado da eliminação do ideal de justificação, de negação da existência de um céu estrelado epistemológico sobre nossas cabeças.

A questão principal que eu gostaria de destacar aqui é a destituição de um suposto valor independente que o conhecimento teria em função de suas qualidades epistemológicas. Assim, é a própria noção de cultura que deixa de ter sentido (READINGS, 1996). Isso porque não há qualquer tipo de conhecimento que ocupe uma posição hierárquica privilegiada, quando comparado com o conjunto de todas as informações disponíveis. Trata-se, do efeito dos valores democráticos no plano da cultura, já que se nega a existência de qualquer vantagem epistemológica para toda forma particular de saber. Dessa maneira, não há mais um conjunto especial de informações que comporiam um patrimônio especial e diferente de todas as demais - o que corresponde exatamente ao conceito de cultura. A cultura, hierárquica por definição, sofre o impacto da afirmação de valores igualitários e isso leva à desarticulação gradual de todos os modelos de privilégios epistemológicos e de todas as posições de superioridade.

Essa crise de autoridade da cultura implica também na decadência de todos os tipos de organizações que antes a incorporavam ou retiravam dos valores superiores a definição de sua própria distinção. Um exemplo de tais instituições é a universidade, se a entendemos sua função como a preparação de cidadãos, como responsável pelo cultivo e desenvolvimento do patrimônio cultural de uma nação. Em um contexto de valores igualitários, não há mais um sentido especial conectado a um conjunto de conhecimentos, nem mesmo aqueles que estariam sob responsabilidade da universidade. Como não há mais tais 
conhecimentos, a universidade também não possui nenhuma autoridade especial nem uma função epistemológica e cultural clara.

Assim, não se trata apenas de crise de sentido da Universidade e sim de uma crise da totalidade da função educacional. A noção de que a educação é um processo de formação, de engrandecimento cultural do indivíduo, de mudança de patamar qualitativo entre um estado inicial inferior e a obtenção de um estado superior no plano da cultura ou do conhecimento, torna-se vítima da mesma carência de sentido hierárquico produzida pelo predomínio dos valores democráticos. Nesse caso, a dificuldade a ser superada consiste na possibilidade de articular os valores democráticos com uma função educativa.

Isso ocorre na medida em que a educação é um processo orientado para um fim que se acredita ser superior: ser educado é melhor do que não ser - independente do sentido que se dê para esse processo. Não havendo mais critérios independentes que garantam a superioridade do ponto de chegada do processo educativo, ele deixa de ser orientado para um fim superior e perde o sentido que possuía na estrutura hierárquica e no mundo da cultura.

A educação democrática é uma educação não teleológica, já que vários processos considerados educativos podem coexistir sem terem que se submeter a um mesmo conjunto de valores unificador, disciplinador e hierarquizador. Assim, as atividades educativas precisam ser redefinidas levando em consideração seus contextos particulares, em função da falência da hierarquia dos valores e da perda de sentido da noção de cultura. Na verdade, a eficácia de um processo educativo passa a ser avaliado a partir de suas próprias características particulares, sem nenhum recurso a valores superiores - algo que pode ser negativamente entendido "excelência sem alma" (LEWIS, 2006, p. 1). 
Essa profunda alteração na condição do saber torna o ethos da travessia uma atitude psicológica senil quando confrontada com o estado atual do conhecimento. Se não há mais um ideal epistemológico, cultural ou educativo desejável e distinto da situação fatual em que nos encontramos em determinado instante, não há mais finalidade rígida. Não há mais necessidade de tensionar uma seta para atirá-la em um alvo distante e inicialmente oculto, porque perdemos a fé na existência de tal alvo. É a crença inicial em um ponto exterior que serve como referência e possibilita articular um sistema do conhecimento cuja marca é a orientação para um fim.

Nesse novo quadro horizontal, não há mais sentido na retenção da energia psíquica como atitude preparatória para a realização de um processo de melhoria epistemológica, cultural ou educativa. A fragmentação tornou sem sentido as noções de processo e de progresso orientados para uma finalidade transcendente. Não há travessia sem que tenhamos a direção e a referência de um ponto de chegada. Se já nos julgamos de posse daquilo que é importante, se já somos dotados de valor, não se requer nenhum deslocamento significativo.

Sendo a seriedade parte do ethos da travessia, ela também não é mais uma atitude requerida pela atual circunstância epistemológica. Ela não passa, hoje, de uma herança formal, de uma atitude psicológica herdada e que ainda é mantida sem a função que a tornou, um dia, necessária. Dentro de um quadro de referências democrático para a epistemologia e a cultura em geral, a seriedade é uma atitude sem função e decrépita.

Nossa relação com a informação ocorre sob a forma de uma tentativa de adaptá-la a finalidades específicas, sempre derivadas de um contexto particular. Não se trata de buscar uma conexão com algo distante e sim de obter funcionalidade. Nesse contexto, as virtudes de um indivíduo para lidar com a informação requerem que ele seja flexível e capaz de se adaptar às circunstâncias. Seus olhos têm de abandonar um horizonte 
epistemológico distante e se concentrarem nas circunstâncias que lhe são dadas. O jogo permanente da multifuncionalidade e da readaptação são atitudes mais apropriadas do que a seriedade.

Essa última não é uma virtude que se faça seguir com necessidade diante de nossa situação epistemológica. A reverência e o respeito estão sendo substituídos por atitudes psicológicas derivadas de um ambiente epistemológico que é mais sutil e rarefeito, em que não se requer mais a rigidez do caráter. Não há mais uma longa viagem a ser empreendida no âmbito do conhecimento. Trata-se, agora, de fazer pequenos ajustes, adaptações e invenções com objetivos específicos.

O conhecimento é um jogo que não requer seriedade porque não estamos mais fora do centro do valor. Não somos mais homens alienados com relação àquilo que é transcendente e superior. Portanto, não devemos a nada reverência e respeito. Nós estamos no centro dos valores e não viajamos mais em direção a algo maior que nós mesmos, não estamos empenhados em chegar a lugares longínquos. A travessia já foi realizada pela reabsorção imanente da fonte dos valores. Nós agora dispomos do conhecimento como "um brinquedo, uma roda que gira por si própria" (NIETZSCHE, 1883/2008, p. 39) sem estar assentada em nenhuma base externa. Nós somos como as crianças que brincam e jogam, mas nossa infantilidade não é um estado imediato que deve ser abandonado em benefício de outro. Ela é o resultado de um longo crescimento em que e nos tornamos mais maduros e flexíveis que os homens mais rígidos. Aos olhos infantis de hoje, os homens sérios são respeitosamente risíveis.

\section{Referências}

ARISTÓTELES. Metafisica. Trad. Valentín Yebra. Madrid: Gredos, 1990. 
BACON, F. Novum organum. São Paulo: Abril Cultural, 1620/1999.

BAUDRILLARD, J. La société de consommation. Paris: Denoël, 1970.

DESCARTES, R. Discurso do método para bem conduzir a própria razão e procurar a verdade nas ciências. São Paulo: Abril Cultural, $1637 / 1979$.

HEGEL, G. W. F. Lecciones sobre filosofia de la religión. Trad. Ricardo Ferrara. Madrid: Alianza Editorial, 1830/1987. 3v.

LEWIS, H. R. Excellence without a soul: how a great university forgot education. New York: PublicAffairs, 2006.

LIPOVETSKY, G. L'empire de l'éphémère: la mode et son destin dans les sociétés modernes. Paris: Gallimard, 1987.

. Le crépuscule du devoir. Paris: Gallimard, 1992.

LYOTARD, J.-F. A condição pós-moderna. Trad. Ricardo Barbosa. $7^{\mathrm{a}}$ Ed. Rio de Janeiro: José Olympio, 1979/2002.

NIETZSCHE, F. A gaia ciência. Trad. Márcio Pugliesi, Edson Bini e Norberto de Paula Lima. São Paulo: Hemus, 1895/1976.

Assim falava Zaratustra. Trad. Antonio C. Braga. São Paulo: Escala, $1883 / 2008$.

READINGS, B. The university in ruins. Cambridge: Harvard University Press, 1996.

SILVEIRA, R. A. T. Fundacionismo e coerentismo: entre a descrição e a normatização. Barbarói, n. 9, jul./dez. 1998, p. 21-34. 